\title{
Sustentabilidade, Empreendedorismo, educação financeira e o plástico no ensino fundamental no desenvolvimento de Produtos educacionais
}

\section{Makir David Mendes Riva 1; Janilse Fernandes Nunes ${ }^{2}$; Lissandro Dorneles Dalla Nora ${ }^{3}$}

\section{RESUMO}

Esse trabalho trata de uma pesquisa em andamento intitulada "Ciência e tecnologia do plástico: um argumento para construção de espaços colaborativos de ensino e da abordagem de práticas sustentáveis na Educação Básica", com apoio da Universidade Franciscana, e financiamento do CNPq. A metodologia está baseada em pesquisa ação de abordagem qualitativa. Tem objetivo de gerar a cultura empreendedora e de educação financeira em uma escola da rede pública municipal, apropriando a comunidade sobre a geração de renda por meio do empreendedorismo associado ao potencial do plástico para a sociedade. Pretendese como resultado a vivência de reciclagem do plástico, contemplada no ensino e na aprendizagem colaborativa, baseada no aprender fazendo, como defendido nos Movimentos Makers, permitindo que comunidades incluam em suas rotinas o empreender e a educação financeira.

Palavras-chave: Empreendedorismo; Finanças pessoais; Jogos educacionais; Meio Ambiente

Eixo Temático: Tecnologia, Inovação e Desenvolvimento Sustentável (TIDS).

\section{INTRODUÇÃO}

Empreender é buscar solução para um problema, nesse sentido, o empreendedorismo social, de um modo geral, busca expandir os conceitos, abordando as questões que afetam a sociedade. Do ponto de vista econômico, envolve planejamento para tornar produto ou serviço mais acessível por meio de técnicas que aperfeiçoem processos e gerem valor social paralelamente. Para Leite

\footnotetext{
${ }^{1}$ Acadêmico de Administração - Bolsista - Universidade Franciscana - UFN. makirriva@gmail.com

${ }^{2}$ Coorientadora. Universidade Franciscana - UFN- janilse@ufn.edu.br

${ }^{3}$ Orientador. Universidade Franciscana - UFN. lissandro@ufn.edu.br
} 
(2010), o empreendedor agregam a visão do benefício social que sua atividade econômica pode impactar antes até do lucro.

Dessa forma, o presente projeto trata-se de uma proposta inspirada no projeto Precious Plastic (DAVE HAKKENS, 2019), para reciclagem do plástico, e contempla formas de ensino e de aprendizagem colaborativas baseadas no aprender fazendo, como defendido nos Movimentos Makers, permitindo que comunidades incluam em suas rotinas o empreender e a educação financeira. Associado a esse desenvolvimento, a participação da Stars aceleradora ${ }^{4}$ permitirá um olhar conectado com o desafio de fomentar o desenvolvimento de soluções inovadoras

Considerando a presença do plástico na sociedade, e a relevância de compreender sobre a tecnologia do plástico, esse projeto justifica-se pela necessidade de incentivar a educação científica e financeira, de maneira a proporcionar a interlocução entre graduação da Universidade Franciscana, e Educação Básica, para assim, desenvolver o espírito empreendedor no ensino de forma a gerar o desenvolvimento de soluções inovadoras para problemas sociais conectadas as potencialidades de apoio pela empresa parceira.

Nesse contexto surge o empreendedorismo social que tem sua base na formação de ações de impacto na sociedade com o objetivo de solucionar ou reduzir problemas sociais ou ambientais. Conforme conceito descrito por Artemísia (2021) que:

O Empreendedor Social aponta tendências e traz soluções inovadoras para problemas sociais e ambientais, seja por enxergar um problema que ainda não é reconhecido pela sociedade e/ou por vê-lo por meio de uma perspectiva diferenciada. Por meio da sua atuação, ele (a) acelera o processo de mudanças e inspira outros atores a se engajarem em torno de uma causa comum. A mudança provocada pelo empreendedor pode ser através de um modelo de negócio, mas não necessariamente, e essa é a principal diferença em relação a negócios sociais. (ARTEMíSIA, 2021)

Moreira (2006) destaca que o processo educacional das pessoas requer conhecer a ciência e seu funcionamento, para que esteja capaz a compreender o lugar onde vive, obter novas oportunidades de renda e se posicionar politicamente consciente da realidade. A escola empreendedora para além de produzir

\footnotetext{
${ }^{4}$ A Stars é uma aceleradora que busca estruturar negócios altamente escaláveis, visando o maior desenvolvimento socioeconômico ao ecossistema de inovação. A aceleradora é a primeira do interior do Rio Grande do Sul e a maior do interior do Brasil.
} 
conhecimento educacional, oferta uma diversidade de aprendizados, aliando prática e teoria o que irá estimular a atuação dos alunos em seus espaços sociais de modo responsável, consciente e financeiramente sustentável.

Tem objetivo de desenvolvimento de produtos educacionais para gerar a cultura empreendedora e de educação financeira em uma escola da rede pública municipal, apropriando a comunidade de instrumentos para a geração de renda por meio do empreendedorismo associado ao potencial do plástico para a sociedade. Promover estratégias a fim de construir a consciência ambiental na Educação Básica e ensino superior, colaborativa, nos moldes preconizados pelo Movimento Maker. Desenvolver oportunidades de empreendedorismo e criação de oportunidades de geração de renda e educação financeira junto à comunidade escolar, aproveitando a oportunidade decorrente do correto destino de resíduos plásticos.

\section{METODOLOGIA}

Embora possa ser aplicada em todas as áreas de conhecimento, o processo de pesquisa-ação que está relacionada com uma atividade na qual haja interação entre seres humanos e entre estes e seu ambiente, encontra a pesquisa-ação na educação uma vocação particular. Assim, o caminho no qual este projeto será conduzido, com etapas e objetivos a serem cumpridos, será utilizada a metodologia de Pesquisa-Ação (THIOLLENT e COLETTE, 2014).

Segundo Thiollent (2005) a pesquisa-ação pode ser dividida em quatro principais etapas: fase exploratória, fase principal, fase de ação e fase de avaliação. A fase exploratória é desenvolvido os encaminhamentos as fases subsequentes da pesquisa, possui um aspecto interno, tem foco ao diagnóstico da situação e das necessidades dos atores e à formação de equipes, e um aspecto externo, que tem por objetivo divulgar essas propostas e obter o comprometimento dos participantes e interessados (THIOLLENT, 2005).

A Fase Principal inicia a prática por meio de seminários para guiar a ação. Os seminários em grupo são operacionalizados, sendo o grupo permanente composto pelos promotores da pesquisa, por integrantes de diversas áreas envolvidas no 
contexto em estudo e por consultores ou pesquisadores externos (THIOLLENT, 2005).

Já a fase de Ação engloba medidas práticas de difusão de resultados, definição de objetivos alcançáveis por meio de ações reais, apresentação de propostas a serem negociadas entre as partes interessadas e implementação de ações-piloto que posteriormente, após avaliação, poderão ser assumidas pelos atores sem a atuação dos pesquisadores (THIOLLENT, 2005).

E concluindo o desenvolvimento da pesquisa-ação, tem-se a fase de Avaliação que apresenta dois objetivos principais: verificar os resultados das ações no contexto organizacional da pesquisa e suas consequências a curto e médio prazo e extrair ensinamentos que serão úteis para continuar a experiência e aplicá-la em estudos futuros. Para o auxílio na trajetória do estudo, a Figura 1 apresenta uma proposta de cronograma sintético de execução.

Figura 1 - Fases, técnicas e períodos de execução da pesquisa

\begin{tabular}{|l|l|l|}
\hline \multicolumn{1}{|c|}{ FASE DO ESTUDO } & \multicolumn{1}{|c|}{$\begin{array}{c}\text { TÉCNICAS A SEREM } \\
\text { UTILIZADAS }\end{array}$} & $\begin{array}{c}\text { PERÍODO PROGRAMADO PARA } \\
\text { EXECUÇÃO }\end{array}$ \\
\hline Fase exploratória & $\begin{array}{l}\text { - Entrevistas } \\
\text { - Observação } \\
\text { - Reuniões } \\
\text { - Análise documental }\end{array}$ & $\begin{array}{l}\text { De setembro de 2021 a novembro de } \\
2021\end{array}$ \\
\hline Fase principal & $\begin{array}{l}\text { - Encontro com os atores } \\
\text { envolvidos no estudo }\end{array}$ & $\begin{array}{l}\text { De dezembro de } 2021 \text { a fevereiro de } \\
2022\end{array}$ \\
\hline Fase de ação & $\begin{array}{l}\text { - Encontro com os atores } \\
\text { envolvidos no estudo }\end{array}$ & De março de 2022 a maio de 2022 \\
\hline Fase de avaliação & $\begin{array}{l}\text { - Observação } \\
\text { - Encontro com os atores } \\
\text { envolvidos no estudo }\end{array}$ & De junho de 2022 a agosto de 2022 \\
\hline
\end{tabular}

Fonte: elaborada pelos autores

Estas etapas serão utilizadas nesta pesquisa porque proporciona ao pesquisador uma postura de observador, permitindo a reunião de informações suficientes para poder explorar, refletir e analisar os dados e, consequentemente, trabalhar na implementação e avaliação das ações adotadas a fim de atingir os objetivos. 


\section{RESULTADOS E DISCUSSÕES}

Estre os resultados esperados no desenvolvimento do presente projeto, e seus desdobramentos na comunidade, parte do efeito mobilizador que permite 0 ganho de autoestima e de uma capacidade coletiva de desenvolver soluções inovadoras associado a diversos temas.

Sendo o plástico, o eixo condutor para o desenvolvimento dos produtos educacionais, a expectativa é a superação do contexto para a diversidade de oportunidades inerentes ao dia a dia em sociedade.

Para isso será desenvolvido durante o desenvolvimento do presente projeto a criação coletiva de produtos educacionais que permitiram a apropriação da comunidade de perspectivas para o desenvolvimento sustentável, o empreendedorismo e a educação para as finanças pessoais e coletivas, impactando do bem-estar da comunidade, permitindo a construção do senso de pertencimento e o potencial de mudar a realidade através de ações coletivas.

\section{CONCLUSÃO}

Com a crescente necessidade de soluções para os problemas da sociedade moderna, inserida no contexto de pandemia, venha a ser nas áreas de saúde, sociais ou ambientais, surgem novos enfoques para o olhar sustentável que requerem a participação de comunidades sob diversas formas e com vários graus de intensidade, que vão desde a participação direta no desenvolvimento dos produtos educacionais até o relacionamento mais complexo com todos os stakeholdes, ou seja, qualquer indivíduo ou organização que, de alguma forma, é impactado pelas ações de uma determinada ação. Em uma tradução livre para o português, o termo stakeholdes significa parte interessada.

A metodologia de pesquisa-ação adquire nesse contexto e para esse estudo, as características de um método flexível para o projeto com equipes interdisciplinares em contato direto com grupos da população ou das comunidades interessadas na resolução dos problemas. Essa metodologia é objeto de experimentação tanto no plano do conhecimento quanto no da prática social. 


\section{QuFN}

\section{AGRADECIMENTOS}

A Universidade Franciscana pela oportunidade de desenvolvimento do presente estudo e ao CNPq pelo apoio através da bolsa do Programa Institucional de Bolsas de Iniciação em Desenvolvimento Tecnológico e Inovação (PIBITI).

\section{REFERÊNCIAS}

DAVE HAKKENS. Creating an Army. Disponível em: https://preciousplastic.com. Acesso em: 27 junho. 2021.

LEITE, E. Incubadora social: a mão visível do fenômeno do empreendedorismo criando riqueza. Recife, 6/12/2010. Disponível em: $<$ http://www.emanueleite.blogspot.com.br/2010/12/incubadorasocial-mao-visiveldo.html?m=1>. Acesso em: 27 de agosto 2021.

MOREIRA, Marco A. A teoria da aprendizagem significativa e sua implementação em sala de aula. Brasília: Editora da UnB. 2006

Thiollent M. Metodologia da pesquisa-ação. 14 ed. São Paulo (SP): Cortez, 2005.

THIOLLENT, Michel Jean Marie; COLETTE, Maria Madalena. Pesquisa-ação, formação de professores e diversidade. Acta Scientiarum. Human and Social Sciences, v. 36, n. 2, p. 207-216, 2014. 